\title{
Article \\ Design of 3D Printing Thermo-Sensored Medical Gear in Detecting COVID-19 Symptoms
}

\author{
Milena Djukanović $^{1, *}$, Ardijan Mavrić ${ }^{2}\left(0\right.$, Jovana Jovanović $^{3}$, Milovan Roganović ${ }^{4,5}$ and Velibor Bošković 6 \\ 1 Faculty of Electrical Engineering, University of Montenegro, Dzordza Vasingtona bb, 81000 Podgorica, \\ Montenegro \\ 2 3D Innovation and Research Startup Center-3Dexperts, Sonnentalstrasse 8, CH-8600 Dübendorf, \\ Switzerland; ardi.mavric@gmail.com or info@3dexperts.ch \\ 3 Faculty of Civil Engineering and Management, University Union Nikola Tesla, 11000 Belgrade, Serbia; \\ jocka747@gmail.com \\ 4 Clinical Centre of Montenegro, Ljubljanska bb, 81000 Podgorica, Montenegro; milovan.roganovic@kccg.me or \\ roganovic.m@ucg.ac.me \\ 5 Faculty of Medicine, University of Montenegro, Krusevac bb, 81000 Podgorica, Montenegro \\ 6 Science and Technology Park Montenegro, Bulevar Mihaila Lalica, 81000 Podgorica, Montenegro; \\ velibor.boskovic@ntpark.me \\ * Correspondence: milenadj@ucg.ac.me
}

Citation: Djukanović, M.; Mavrić, A.; Jovanović, J.; Roganović, M.;

Bošković, V. Design of 3D Printing Thermo-Sensored Medical Gear in Detecting COVID-19 Symptoms. Appl. Sci. 2021, 11, 419. https://doi.org/ 10.3390/app11010419

Received: 30 November 2020 Accepted: 29 December 2020 Published: 4 January 2021

Publisher's Note: MDPI stays neutral with regard to jurisdictional clai$\mathrm{ms}$ in published maps and institutional affiliations.

Copyright: (C) 2021 by the authors. Licensee MDPI, Basel, Switzerland. This article is an open access article distributed under the terms and conditions of the Creative Commons Attribution (CC BY) license (https:// creativecommons.org/licenses/by/ $4.0 /)$.
Abstract: Shortly after the outbreak of the COVID-19 pandemic, there was a need to provide protective equipment to the medical facilities whose supplies were threatened to be depleted. Just like many countries in Europe, Montenegro responded to the need for medical equipment by using the advantages of 3D printers while establishing a state network of production hubs, ensuring closed connectivity, communication, and the mutual fulfilment of personal protective equipment (PPE) demands whenever and wherever required. With the second wave of the pandemic, Montenegro rose to second place in the world with the number of coronavirus cases, which also led to an increasing number of infected medical staff. Since fever is a frequent symptom of SA+RS-CoV2 infection, a type of innovative 3D-printed thermo-sensored medical gear has been designed and tested in hospital conditions. This medical gear shaped like a bracelet, which changes color in the presence of high human body temperatures, proves to be efficient and easy to use for medical staff as well as patients.

Keywords: COVID-19; additive manufacturing; thermo-sensored filament; 3D printing; 3D printing medical gear

\section{Introduction}

One of the most revolutionary technologies of this century-additive manufacturing, also known as 3D printing-has performed crucial roles in many applications, with the most important being in medicine, architecture, industry, and art [1-3]. The 3D printing process builds three-dimensional objects using a computer-aided design (CAD) model while successively adding filaments (e.g., plastic, ceramics, metal, or steel) layer by layer. In the time of the Coronavirus Disease 2019 (COVID-19) pandemic, 3D printing has shown great potential and has a leading role in providing spare parts for medical devices and protective gear due to the unavailability of supplies [4].

Shortly after the outbreak of the COVID-19 pandemic in Montenegro, there was a need to provide protective equipment to the medical facilities whose supplies were threatened to be depleted soon after the virus arrived in the country. Due to the pandemic, supply chains were having difficulties functioning, so the potential procurement of additional equipment could require a long waiting period. Some countries that faced a pandemic before Montenegro responded to the need for medical equipment by using the advantages of 3D printers that were available to various entities at the time [5]. As such, similar to other European countries such as Austria, Belgium, Denmark, Germany, and Switzerland, a coalition of 
enthusiastic Montenegrin 3D Printing makers and manufacturers have decided to step up in response to the COVID-19 crisis in order to connect and establish a state network of production hubs, ensuring closed connectivity, communication, and the mutual fulfilment of personal protective equipment (PPE) demands whenever and wherever required. It all started with the initiative at the Faculty of Electrical Engineering of the University of Montenegro and the Science and Technology Park Montenegro, supported by the Ministry of Science in Montenegro, while gathering all 3D printers in the country (45 printers in Montenegro) to create a national cluster, printing certain segments of protective equipment and spare parts that were made available to the Institute of Public Health of Montenegro [6]. It was decided to start printing prototypes based on available 3D models: protective masks for respirators along with tubes, protective masks with HEPA filters (filters with strong drafting power), and protective visors. After the Institute of Public Health of Montenegro verified the quality and safety of the printed equipment, the National Coordination Body for Infectious Diseases decided that the Science and Technology Park Montenegro will be the main coordinator of 3D printing in Montenegro, in order to centralize the entire system through one platform and help the supply process run faster and without interruption. In addition, noticing the efforts of the cluster, the National Coordination Body decided to provide financial assistance to the cluster for procurement of the necessary filaments since, due to the intensive use of available filaments, 3D producers soon ran out of their stock. To date, over 19,000 protective visors have been delivered to the community, including an estimate of more than 50 different entities, primarily medical institutions (see Figure 1).

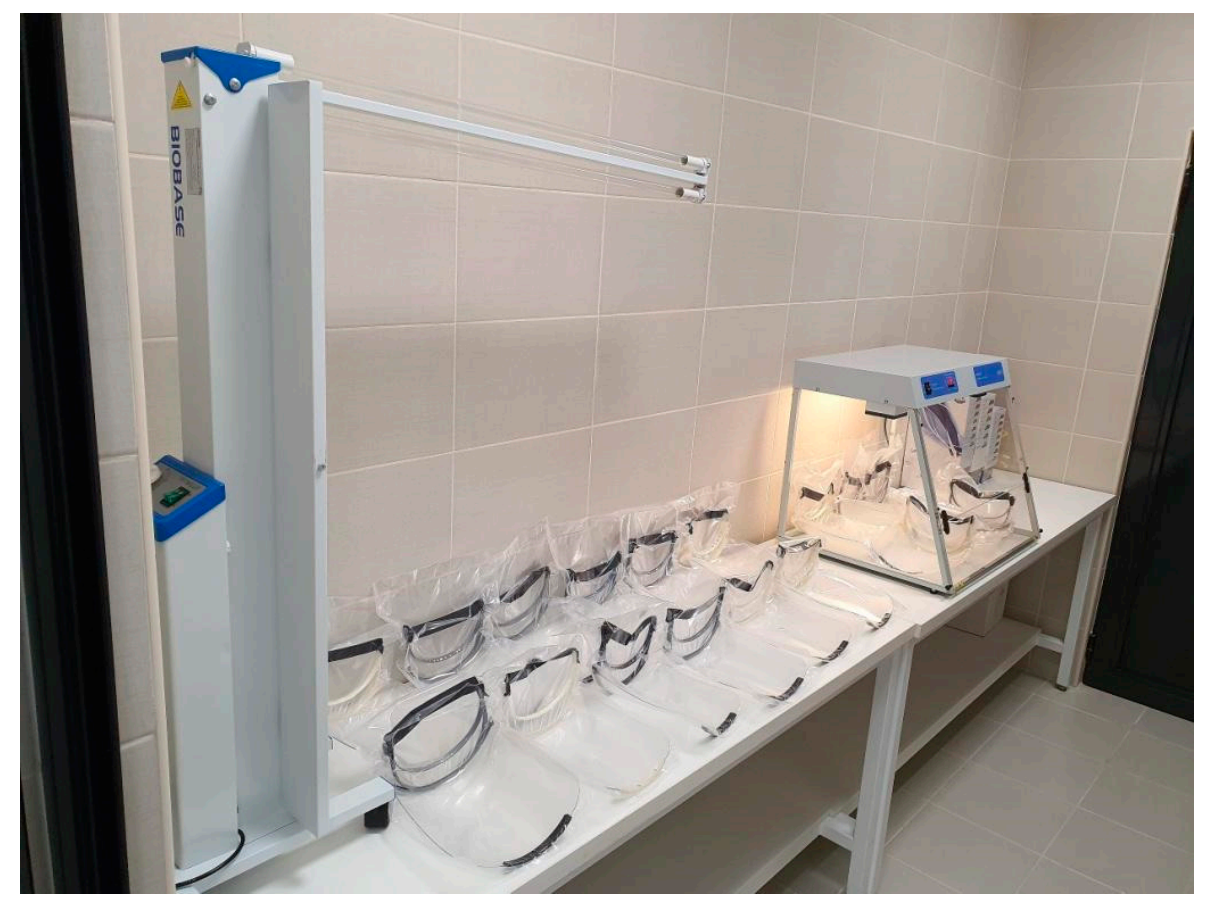

Figure 1. Printed protective visors at the Science and Technology Park Montenegro.

The Clinical Center of Montenegro (CCM), as the largest health care institution in Montenegro and the only health care institution at the tertiary level of health care, has been involved in the treatment of patients with the new disease since the beginning of the COVID-19 epidemic. One of the biggest challenges for the entire health system, including the CCM, has been to provide personal protective equipment (PPE) for health workers. The type and amount of PPE that should be used when treating a patient with COVID-19 varies based on the clinical job and setting [7]. For both health workers working in triage centers and those working in intensive care units, wearing protective visors provides an additional degree of protection for the nose, mouth, and accessible mucous membranes [8]. 
Thus, they should not be the primarily used PPE against a respiratory infection such as COVID-19, but as an additional level of protection, they are definitely recommended [9].

The joint efforts of the national cluster and donors have led to the necessary amount of PPE, significantly contributing to the effectiveness in the fight against the new virus in Montenegro, which was among the first countries in the world to become a coronavirusfree country [10]. However, problems have arisen in the second wave of the epidemic up to now (November 2020), when there is a huge and increasing mortality rate due to overwhelmed medical infrastructure at the national level, putting Montenegro at second place with the number of COVID-19 cases [11]. At a time when there is an increasing number of infected medical workers, when doctors of all specializations are involved in working with COVID-19 patients, and when there is talk of a potential collapse of the health system, 3D-printed PPE is not enough; additional medical equipment that is easy to use and easily accessible is badly needed.

In most studies to date, fever has been shown to be a frequent symptom of SARS-CoV2 infection [12]. Body temperature testing is a very commonly used method in COVID-19 screening, and in patients with COVID-19 (especially in intensive care units [13]), the body temperature is measured several times during the day in accordance with hospital protocols. Additionally, the presence or absence of fever is often one of the deciding factors in the treatment of COVID-19 patients [14]. In a situation where the clinical picture of COVID-19 patients is changing rapidly and unexpectedly, it is crucial to have information on whether the patient has an elevated body temperature at any moment. Given the overload of healthcare professionals, innovative solutions for detecting a fever would be of great importance.

This paper aims to present research regarding 3D printing of tri-color change filaments and thermochromic paint as part of a piece of medical gear which can be used for detecting high body temperatures $[15,16]$. Extensive material analysis is done both in laboratory and hospital conditions. In Section 2, we define the used materials, sample shapes, and process analysis. The results are presented in Section 3 and give precise insight on the tested materials and their color and time change, along with the proposal of a thermo-sensored medical gear design that can implement both of these materials in order to detect high body temperatures and justify the use of this gear in hospitals for medical staff as well as patients.

\section{Materials and Methods}

\subsection{Materials}

The goal of this study was to analyze the sensitivity and color hue of 3D printing materials at different temperatures, reaction times, shapes, and density models. All investigations were conducted on a PLA (PolyLactic Acid) tri-color change filament and thermochromic paint, as well as a combination of these two different materials. To date, there is a small number of manufacturers on the market producing filaments with colorbased sensitivity to changes in temperature. For these investigations, we used two different types of filaments: a PLA tri-color change filament $(1.75 \mathrm{~mm})$ and thermochromic paint.

The output data of the analyzed materials at different shapes, densities, and temperatures were obtained during two analysis processes: one in laboratory conditions with a controlled, constant temperature and the other using a human body temperature and its influence on these materials in hospital conditions.

When describing the composite structure of the PLA tri-color change filament or even any other PLA filament, users are confronting a limitation, because all manufacturers of these materials are keeping their respective colorant additives proprietaries as trade secrets [17]. In general, thermochromic materials reversibly change their color by a temperature change, and that color change is due to a change in crystalline phase and structure [18]. PLA tri-color change filaments are made of an ordinary PLA filament material, combined with thermochromic pigments that have been incorporated into them during the production phase, such as common white coatings, colored paintings, and white textile 
membrane coverings [19]. Thermochromic materials are mixtures composed of the color former, the color developer, and the solvent. Usually, the color former is a cyclic ester and defines the base color, while the color developer is a weak acid and produces the color change and the final color intensity. The solvent (alcohol or ester) melting point affects the color transition temperature, which can be designed for a specific application.

The first analyzed filament was the tri-color PLA 3D-printed temperature change lava filament, which changes color based on the temperature, as shown in Figure 2. When the temperature is below $33^{\circ} \mathrm{C}$, the filament stays in its original black color. The color of the filament changes from black to orange when the temperature goes above $33^{\circ} \mathrm{C}$, and the filament color changes from orange to yellow when the temperature goes above $45^{\circ} \mathrm{C}$. The longer the exposure time, the faster the color fades.

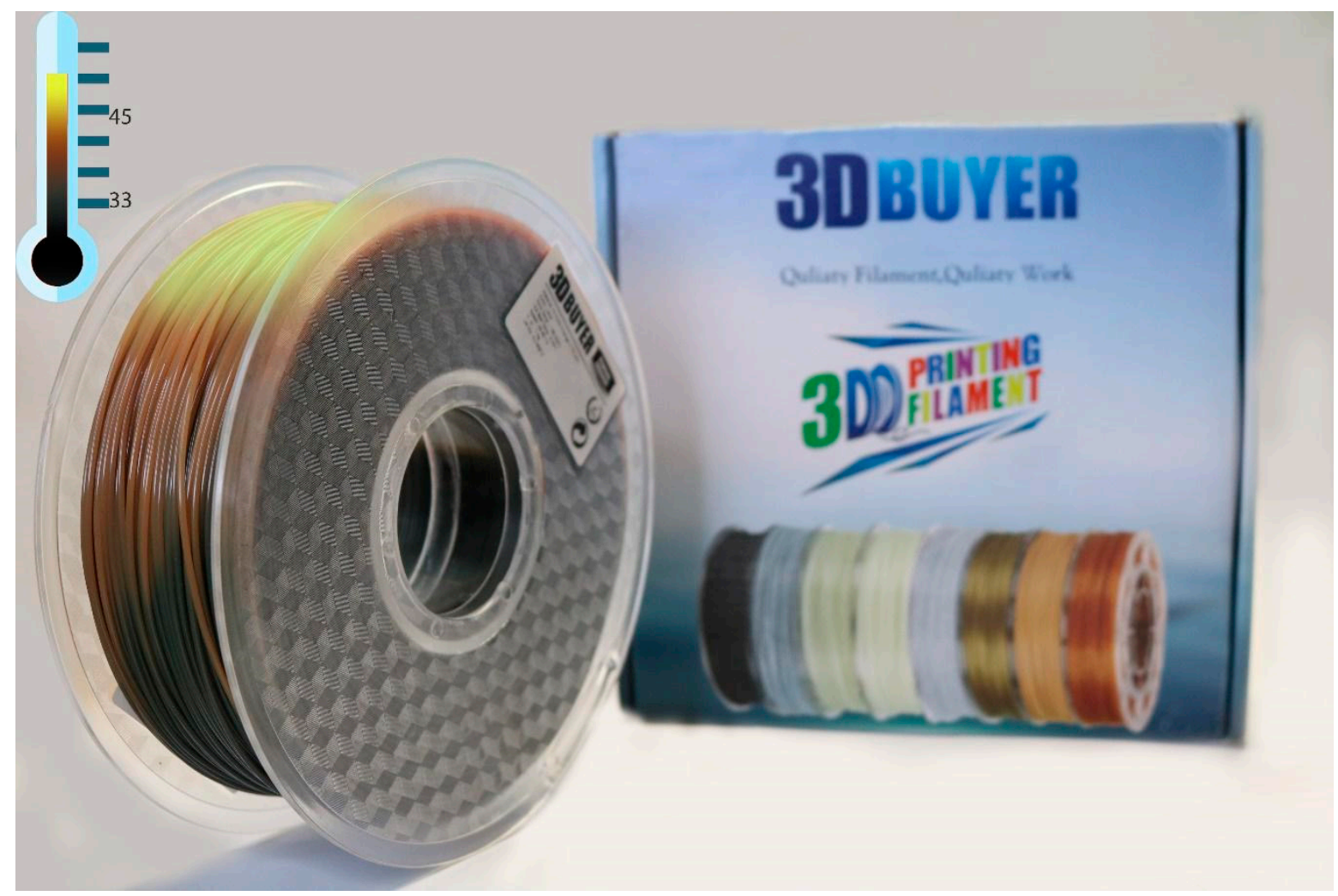

Figure 2. PLA tri-color thermochromic lava filament.

Atlanta Chemical Engineering LLC, Atlanta, GA (USA) thermo color-changing (thermochromic) paints are top-quality materials applied on paper, wood, metal, and plastic surfaces, as shown in Figure 3. They come with different activation temperatures to change from a color to colorless (translucent white) or a color to a color transition. Thermochromic paints have good consistency and excellent dye properties [20]. These products are waterbased, non-toxic, and change color reversibly, except for those which are marked as irreversible. The irreversible thermochromic paints change color just once at the indicated activation temperature.

Depending on how and where we want to use it, thermochromic paint can be found in several forms, such as pre-fabric paints, liquid inks, screen printing inks, and thermochromic pigments [21]. They are produced in different colors and temperature sensitivities, with temperature ranges from $12{ }^{\circ} \mathrm{C}$ to $70^{\circ} \mathrm{C}$. The imprinted object may change color when touched if the ambient temperature is no more than $4-5$ degrees below $33^{\circ} \mathrm{C}$. 


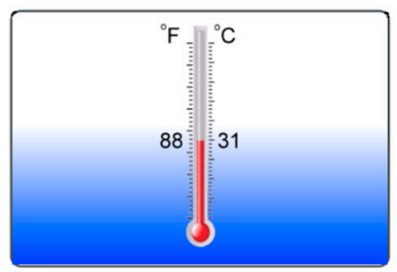

Blue-Colorless $88^{\circ} \mathrm{F}\left(31^{\circ} \mathrm{C}\right)$

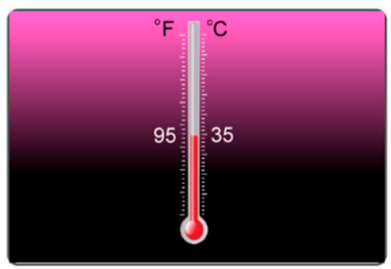

Black-Pink $95^{\circ} \mathrm{F}\left(35^{\circ} \mathrm{C}\right)$

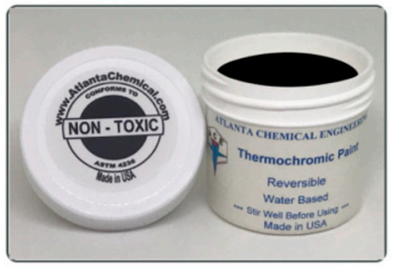

Black-Colorless $88^{\circ} \mathrm{F}\left(31^{\circ} \mathrm{C}\right)$

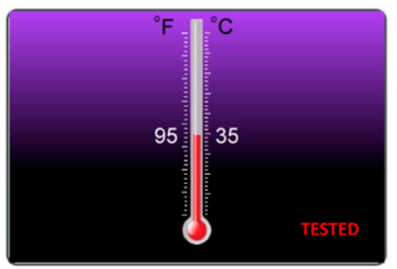
Black-Purple
$95^{\circ} \mathrm{F}\left(35^{\circ} \mathrm{C}\right)$

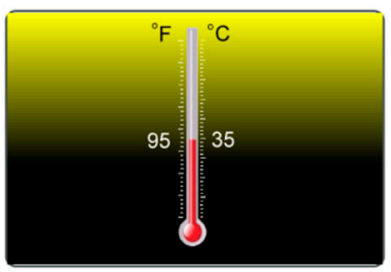

Black-Yellow

$95^{\circ} \mathrm{F}\left(35^{\circ} \mathrm{C}\right)$

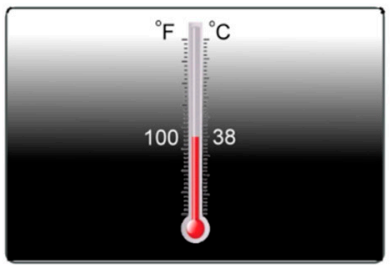

Black-Colorless

$100^{\circ} \mathrm{F}\left(38^{\circ} \mathrm{C}\right)$
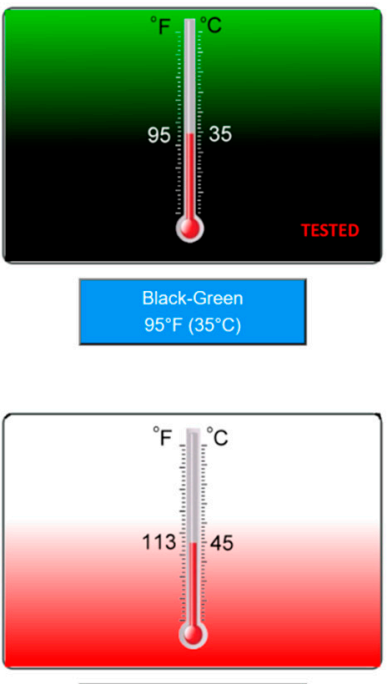

Red-Colorless $113^{\circ} \mathrm{F}\left(45^{\circ} \mathrm{C}\right)$

Figure 3. Temperature values and variety of thermo color-changing (thermochromic) paints [22]. Reproduced with permission from Atlanta Chemical Engineering LLC, Atlanta, GA (USA), Copyright publisher, 2020.

For this analysis, a thermochromic paint material was used, with color-changing black-pink $35{ }^{\circ} \mathrm{C}$ and black-green $35{ }^{\circ} \mathrm{C}$ selected since they best show the change in body temperature from $36.5^{\circ} \mathrm{C}$ to $37^{\circ} \mathrm{C}$ and up, which would best identify the rise in temperature known as one of the symptoms of COVID-19.

\subsection{Process Parameters}

The mechanical, dimensional, and surface finish properties of the parts, fabricated using fused filament fabrication (FFF) technology, depend on the selection of the process parameters [23,24]. In this study, four different 3D models were designed in AutoCAD Fusion 360 software [25]. They were defined as follows: cube block (Model 1), pyramid (Model 2), cube block with the subtracted pyramid (Model 3), and pyramid with the subtracted pyramid (Model 4), as shown in Table 1. In Models 3 and 4, the principle of subtracting the pyramidal shape from the bottom part of the basic objects of the cube and the pyramid was applied. In order to focus on the sensitivity and color hue of the materials at different temperatures and the reaction times of the PLA tri-color change materials, FFF process parameters such as the layer thickness (height), feed rate, air gap, raster angle, and temperature were fixed for all the sample models.

Table 1. Types of designed 3D models.

\begin{tabular}{cccc}
\hline $\mathbf{n .}$ & Model Name & Layer Height $(\mathbf{m m})$ & Dimensions $(\mathbf{m m})$ \\
\hline 1. & Cube block & $1-5$ & $30 \times 30$ \\
\hline 2. & Pyramid & $1-5$ & $30 \times 30$ \\
\hline 3. & Cube block with subtracted pyramid & $1-5$ & $30 \times 30$ \\
\hline 4. & Pyramid with a subtracted pyramid & $1-5$ & $30 \times 30$ \\
\hline
\end{tabular}

Each of the four models mentioned above had the same dimensions at the base $(30 \mathrm{~mm} \times 30 \mathrm{~mm}$ ), and each set of models consisted of five specimens, where the layer thickness started at $1 \mathrm{~mm}$ for the first specimen and increased up to the fifth specimen at $5 \mathrm{~mm}$ in steps of $1 \mathrm{~mm}$, as shown in Figure 4. 


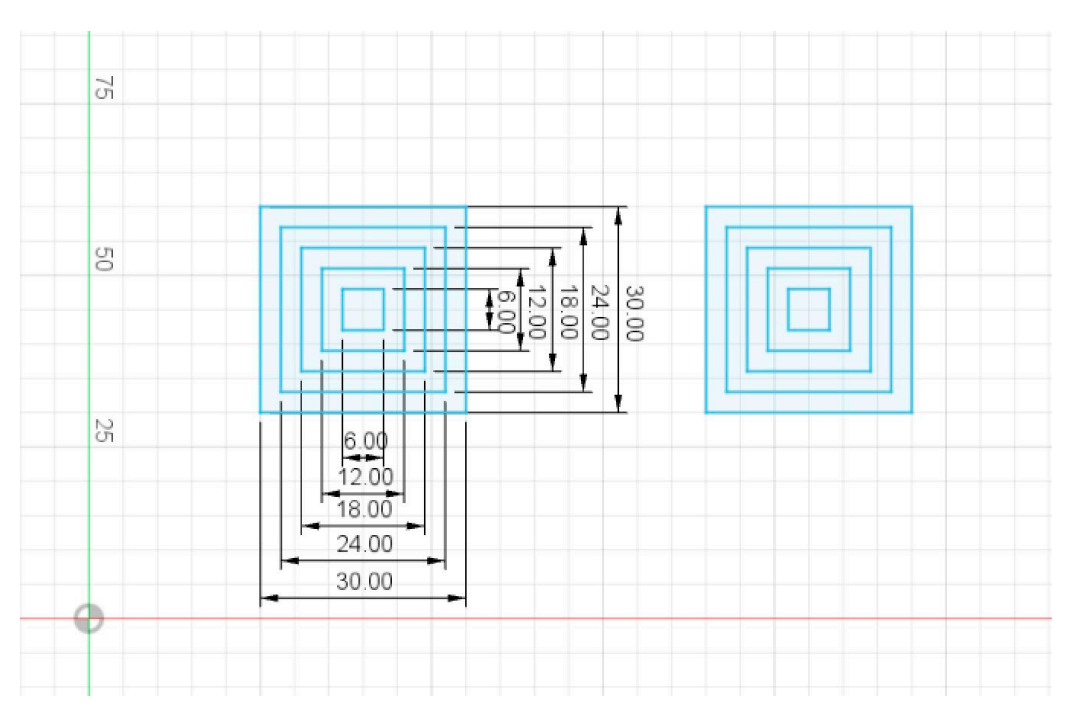

Figure 4. Design and dimensions of the base for all four models.

Models 2 and 4 had the shape of a stepped pyramid with five steps, and the distance between the step and the edge of the platform was $3 \mathrm{~mm}$ while the height of the step at the pyramid varied from 0.2-1.0 mm. For example, in the case of Model 2, a stepped pyramid with five steps, where its height was $4 \mathrm{~mm}$ (fourth specimen), had a distance of $3 \mathrm{~mm}$ from the step to the edge of the platform. Because of this, the step height would be $0.8 \mathrm{~mm}$. In Model 4, the subtracted stepped pyramid from the bottom side had three steps, where the width and height of the steps was identical to the dimensions of the steps of the stepped pyramid on the outside.

All four designed models are presented in appropriate columns (1-4) with five different specimens in Figure 5. Figure 5a shows a view from the top, while in Figure 5b, a view from the bottom of the models can be seen. All four models were sliced in CraftBot Budapest Hungary CraftWare CW_1.23_WIN_x64 software [26] and printed with a CraftBot Budapest Hungary Flow Idex XL 3D printer [27] using a PLA tri-color change filament.

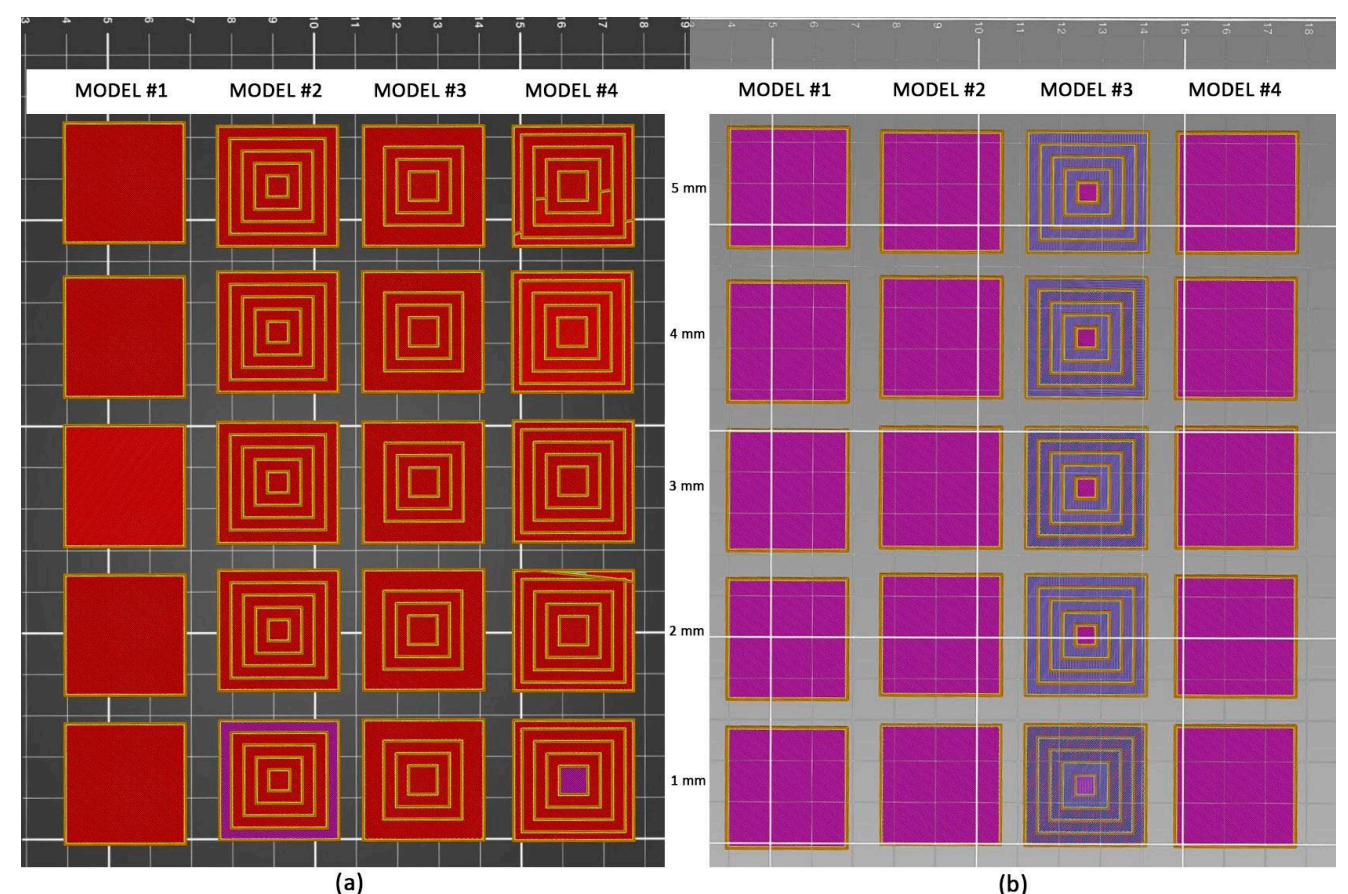

Figure 5. (a) Models' top view, and (b) models' bottom view. 


\subsection{Process Analysis}

Process analysis of the two different types of 3D printing materials consisted of two analysis parts: the PLA tri-color thermochromic filament and the thermochromic paint. The first analysis part focused on testing each specimen (five of them) for all four designed models at different temperatures, but each temperature was kept at a constant value for up to $5 \mathrm{~min}$. At the same time, the sensitivity and time during which the filament color changed were measured. The PLA tri-color change 3D printing filament changed its color based on the temperature, and this change started above $33^{\circ} \mathrm{C}$, changing the filament from black to a dark orange color. During the time that the temperature was below $45^{\circ} \mathrm{C}$, the filament would gradually change color from dark orange to yellow, after which the filament color turned yellow. The longer the exposure time, the faster the color faded.

In the second part of the process analysis, investigations for the thermochromic filament were done in several ways and under several conditions. Firstly, we combined the thermochromic color with the PLA standard and PLA tri-color change filament for the test while using different layer thicknesses. For the second method, PET (Polyethylene Terephthalate) transparent foil was used, with the paint being applied on it. For this analysis, a thermochromic paint with green and purple colors sensitive to a temperature of $35^{\circ} \mathrm{C}$ was used. For its practical testing, a model in the form of a medical bracelet was designed. The paint could be applied using a brush, paint roller, or airbrush. For airbrushing, the air pressure should be between 70-80 PSI. The coating dry time at room temperature depended on the nature of the painted surface and air humidity, and the process could last from $1 \mathrm{~h}$ to $12 \mathrm{~h}$. All prepared samples (PLA, PLA tri-color change, and PET) were first tested at a constant temperature to identify the temperature at which the color shade changed from black to another color. Afterward, the samples were tested in realistic conditions, those being directly at human body skin temperature in hospital conditions.

In cooperation with the Clinical Center of Montenegro, direct measurements on patients with high body temperatures $\left(37.2{ }^{\circ} \mathrm{C}\right.$ and $\left.37.5^{\circ} \mathrm{C}\right)$ were conducted in hospital conditions. For the first part of the process analysis, for all four designed models and each of the five PLA tri-color change specimens, the time of the material's color change was measured directly on the patient (Supplementary Materials, Figure S1). For example, the results for the cube block model (Model 1) at a temperature of $37.2{ }^{\circ} \mathrm{C}$ showed a color change at 12,30,65, 115, and $490 \mathrm{~s}$ for five specimens with different layer thickness from 1 to $5 \mathrm{~mm}$, respectively. The tested material was put on the hand and wrist in the shape of a bracelet.

For the second part of the process analysis, the thermochromic paint material was tested on the hand and wrist. At the temperature of $37.2{ }^{\circ} \mathrm{C}$, the color changed from black to dark green in $10 \mathrm{~s}$. For the other temperature value of $37.5^{\circ} \mathrm{C}$, the color changed from black to an intense green in $10 \mathrm{~s}$ as well. Therefore, the higher the temperature, the more intense and clearer the color became (Supplementary Materials, Figure S2).

\section{Results}

\subsection{Results of the PLA Tri-Color Thermochromic Filament}

As noted in the previous section, we analyzed and obtained results for four specific models and five subspecies of each model. We tested each of the specimens at temperatures from $35^{\circ} \mathrm{C}$ to $40{ }^{\circ} \mathrm{C}$ and measured the time when there would be a change of color on the last layer of the object (filament). In Model 1, the first specimen had a layer thickness of $1.0 \mathrm{~mm}$, while every subsequent layer had a thickness which increased by $1.0 \mathrm{~mm}$. The measurement results show that the first two specimens with layer thicknesses of $1.0 \mathrm{~mm}$ and $2.0 \mathrm{~mm}$ layer were the most sensitive, and below each temperature both reacted almost the same, while the color of the object changed at approximately the same values (15-36 s), as shown in Figure 6. In specimens 3, 4 and 5, we noticed that at a temperature of $35^{\circ} \mathrm{C}$, their colors changed 4-15 times slower than in the first two specimens. Observing all the data we obtained at temperatures from $35^{\circ} \mathrm{C}$ to $40{ }^{\circ} \mathrm{C}$, we recognized that the color 
changed exponentially, being 1.8-2.3 times faster depending on the temperature value. The average speed at which the color of the material changed in Model 1, including all specimens, was 1.9 times between the lowest and highest temperature.

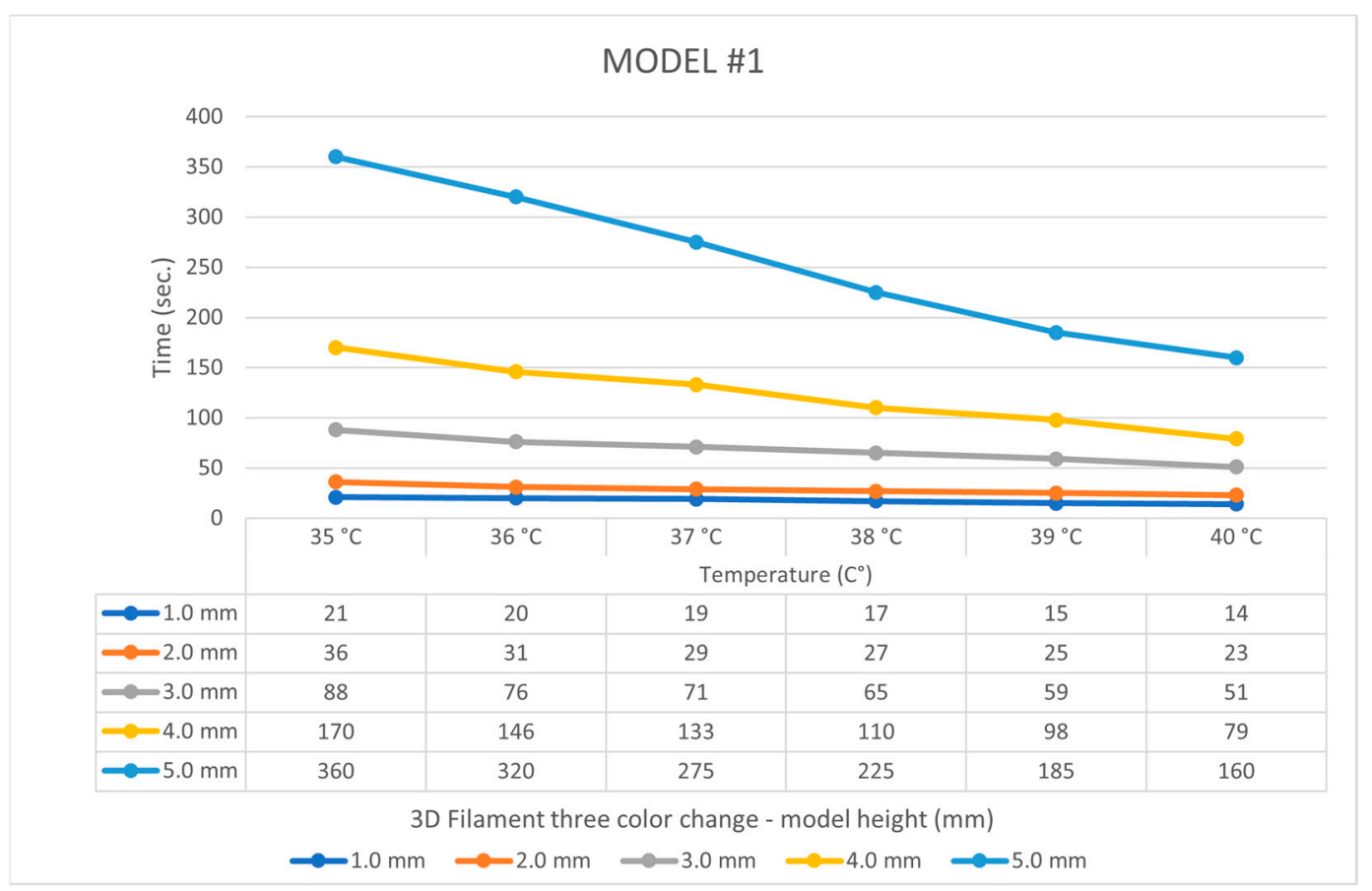

Figure 6. Diagram and time data for Model 1.

Model 2 had the form of a stepped pyramid and consisted of five steps. The thickness of the base layer of the pyramid in the first specimen was $0.2 \mathrm{~mm}$, and the height of the fifth layer was $1.0 \mathrm{~mm}$. The other four specimens had layer thicknesses as follows: $0.4 \mathrm{~mm}-2.0 \mathrm{~mm} ; 0.6 \mathrm{~mm}-3.0 \mathrm{~mm} ; 0.8 \mathrm{~mm}-4.0 \mathrm{~mm}$; and $1.0 \mathrm{~mm}-5.0 \mathrm{~mm}$. The results of Model 2 show that the shape of the stepped pyramid significantly affected the temperature transmission through the material (Supplementary Materials, Table S1). From the data of Model 2, we can conclude that the time interval for the color change of the filament was almost approximate for each temperature value from $37^{\circ} \mathrm{C}$ to $40^{\circ} \mathrm{C}$, with time variations up to $30 \%$, depending on the specimen and layer thickness of the object. Through the diagram (Supplementary Materials, Table S2), it can be more clearly seen that the first four specimens of the stepped pyramid had approximately constant values for temperatures higher than $37^{\circ} \mathrm{C}$, which leads to the conclusion that these four species at temperatures from $37^{\circ} \mathrm{C}$ to $40^{\circ} \mathrm{C}$ would have identical material colors.

Models 3 and 4, having the shapes of a cube block with a subtracted pyramid and a pyramid with a subtracted pyramid, respectively, proved to be models that were more resistant to temperature transmission compared with the previous two models. From the diagrams of these two models (Supplementary Materials, Table S3 and S4), it can be concluded that the resistances of these two models were higher up to a temperature of $37^{\circ} \mathrm{C}$. Above that temperature, the temperature transmission was faster, which in practice means that the color of the object (model) would change faster. Therefore, we can conclude that these two models gave better results for identifying elevated body temperatures, as demonstrated in Figure 7. 


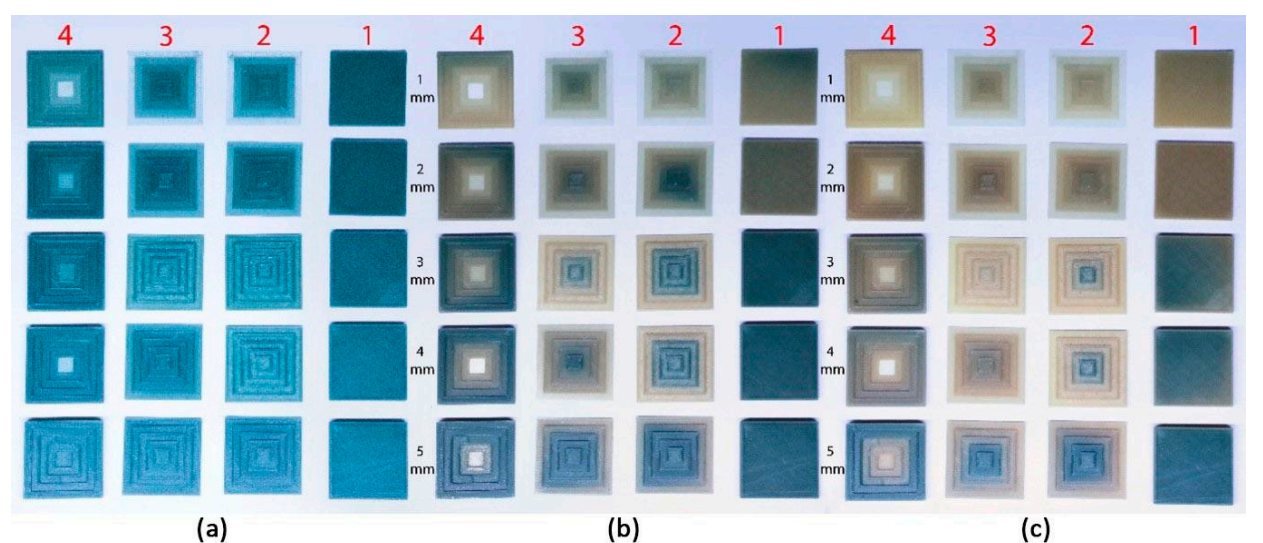

Figure 7. The appearance of the PLA tri-color thermochromic filament during temperature exposure when (a) not exposed to the temperature, or when it was below $33^{\circ} \mathrm{C}$; (b) heated to $37^{\circ} \mathrm{C}$; and (c) heated to $40^{\circ} \mathrm{C}$.

In the next three pictures (see Figure 7), one can see the appearance of the four models and its five specimens with a layer thickness of $1.0-5.0 \mathrm{~mm}$, showing how the color change of the material looked when exposed to temperatures of $37^{\circ} \mathrm{C}$ and $40^{\circ} \mathrm{C}$, as well as how the model looked before being exposed to those temperatures or when the temperature was below the $33^{\circ} \mathrm{C}$.

\subsection{Results of the Thermochromic Paint}

When analyzing the thermochromic paint with a color change occurring at $35^{\circ} \mathrm{C}$, we came to several conclusions about how this paint behaved at a constant temperature maintained in laboratory conditions and how it behaved under realistic conditions, namely when directly at human body skin temperature in hospital conditions. As we combined the PLA filament and thermochromic paint, we concluded that the layer thickness of the PLA material performed a significant role in when the color change would be activated in the thermochromic paint. The main conclusion is that the thinner the layer was, the faster the color change was activated.

The first result for using thermochromic paint $\left(35^{\circ} \mathrm{C}\right)$ with PLA standard materials (see Figure 8) having a layer thickness of $0.4 \mathrm{~mm}$ led to the fact that the paint was activated at $36.5^{\circ} \mathrm{C}$ in laboratory conditions, while in realistic conditions, the activation of the paint followed at a temperature of $38.5^{\circ} \mathrm{C}$. As such, for use with PLA standard materials, it is recommended to use a thermochromic paint that is activated in the range from $30^{\circ} \mathrm{C}$ to $32{ }^{\circ} \mathrm{C}$.

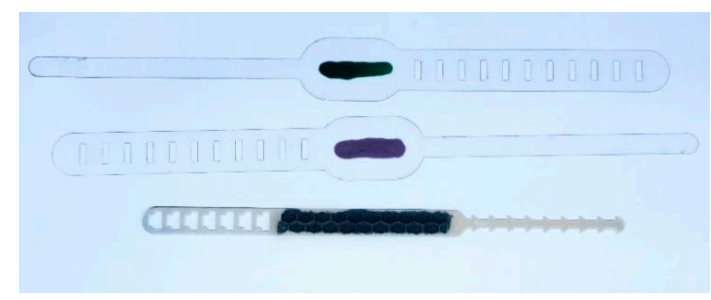

(a)

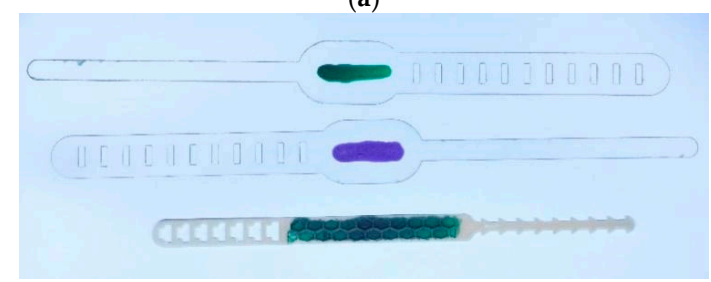

(b)

Figure 8. Thermochromic paint when (a) not exposed to a higher temperature and (b) exposed to a temperature of $37^{\circ} \mathrm{C}$. 
The second result, which we obtained using thermochromic paint $\left(35^{\circ} \mathrm{C}\right)$ with a PLA tri-color change filament (see Figure 8) with a layer thickness of $0.4 \mathrm{~mm}$, showed that in laboratory conditions, the paint would activate at $36{ }^{\circ} \mathrm{C}$, while in realistic conditions, the activation of the paint followed at a temperature of $38^{\circ} \mathrm{C}$. Therefore, in combination with the PLA tri-color change filament, it is recommended to use a thermochromic paint that is activated in the range from $30^{\circ} \mathrm{C}$ to $33^{\circ} \mathrm{C}$.

The best result with thermochromic paint $\left(35^{\circ} \mathrm{C}\right)$ was obtained when we applied it on a PET transparent foil (see Figure 8) with a thickness of $0.2 \mathrm{~mm}$; in laboratory conditions, the paint was activated at $35.0^{\circ} \mathrm{C}$, while in realistic conditions, the activation of the paint followed at a temperature of $37.5^{\circ} \mathrm{C}$. Therefore, in combination with the PET foil, it is recommended to use thermochromic paint that is activated in the range from $33^{\circ} \mathrm{C}$ to $35^{\circ} \mathrm{C}$.

During testing, we arrived at another conclusion, which was that the thermochromic paint proved to be stable in the identification of a particular temperature. Additionally, its reversible color-change property contributed to the fact that objects prepared with thermochromic paint were not single-use; they could be used multiple times.

\subsection{Medical Gear Design}

The bracelet design was done in software for 3D modelling-Dassault Systèmes, Vélizy-Villacoublay, France, SolidWorks 2017 [28]—and consisted of two different parts. The first part was a static PLA bracelet that fit the human wrist, and inside of it was placed a second part made with a PLA tri-color change filament, as shown in Figure 9. It needs to be mentioned that instead of a PLA tri-color change filament, thermochromic paint applied on the surface of the PET transparent foil could also be used. When the first part has been printed on a CraftBot Flow Idex XL 3D printer with a dual head, it becomes capable of rotating its subparts via a printed shaft, thus adapting the bracelet to the curvature of the wrist.

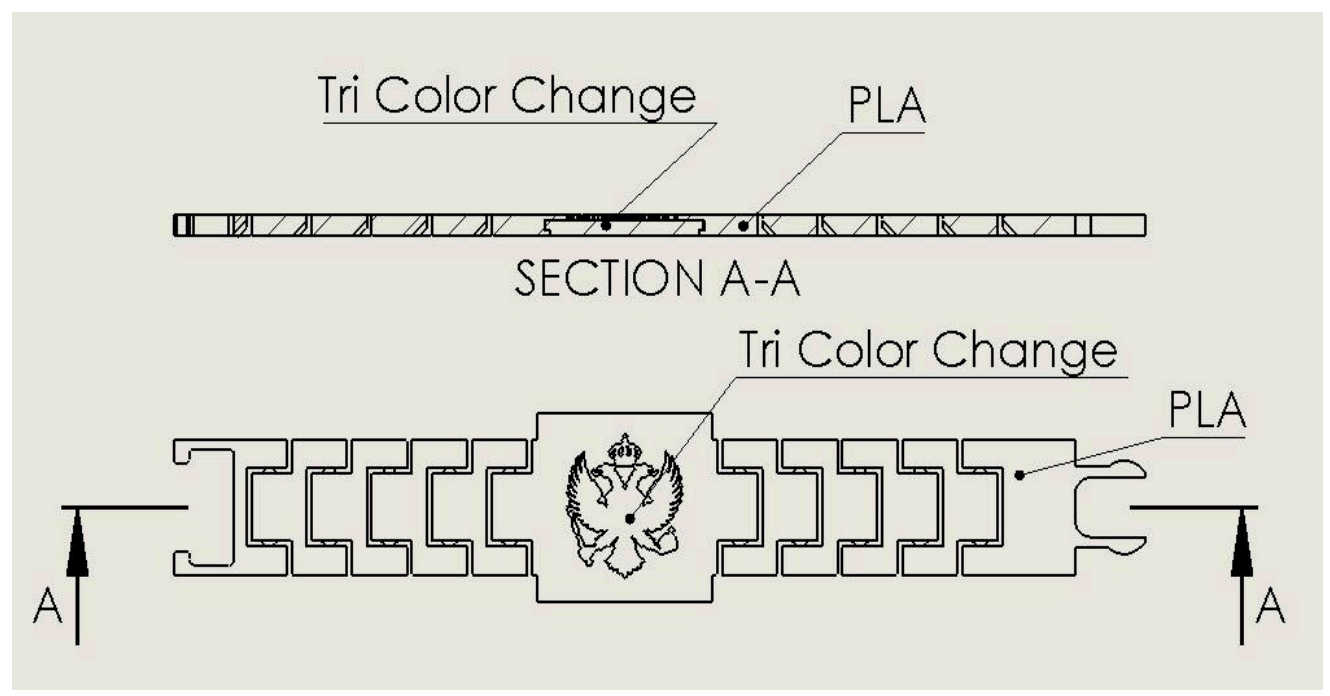

Figure 9. 2D drawing of bracelet-shaped thermo-sensor medical gear.

Since a CraftBot Flow Idex XL with a dual head was used for printing this braceletshaped medical gear, the model can be printed in one part, illustrated in Figure 10. Craft Ware software was used for slicing the model with a $0.4 \mathrm{~mm}$ nozzle and a $0.1 \mathrm{~mm}$ layer height. 


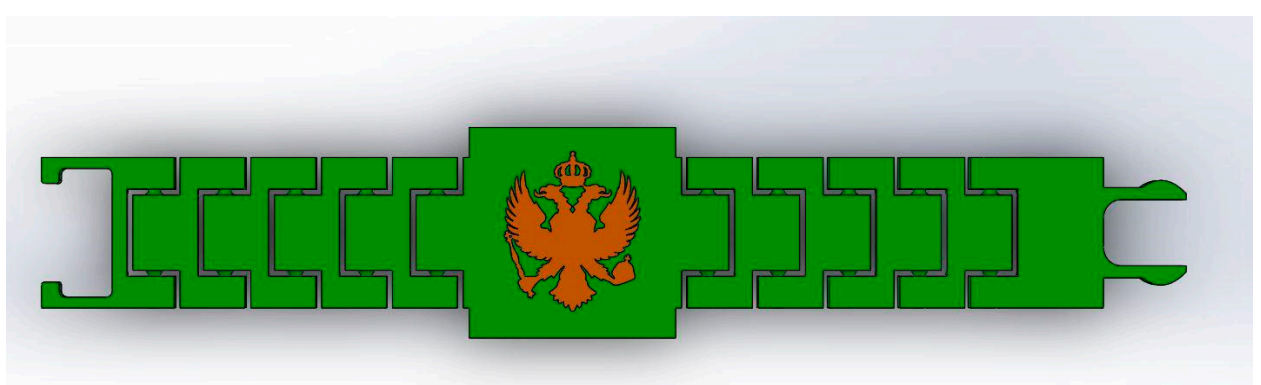

(a)

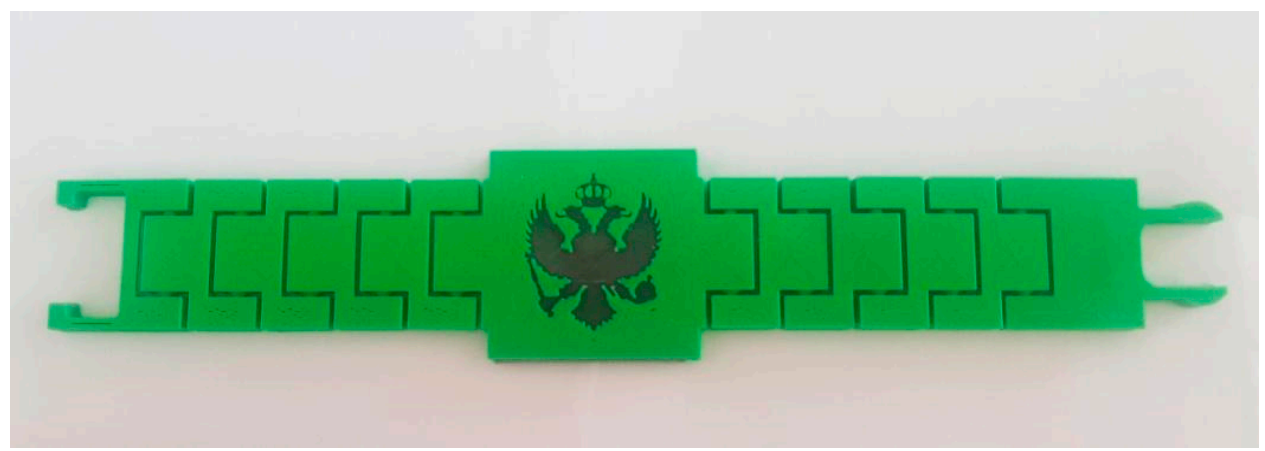

(b)

Figure 10. (a) Software 3D model and (b) 3D-printed model.

3D-printed medical gear in the shape of a bracelet shows two different behaviors. When the temperature is below $37^{\circ} \mathrm{C}$, the inside of it stays gray (i.e., the color-changing filament is in one stage), but when the temperature rises above $37^{\circ} \mathrm{C}$, it changes to an orange color (i.e., the color-changing filament goes to the second color stage), as shown in Figure 11. This has been tested in hospital conditions.

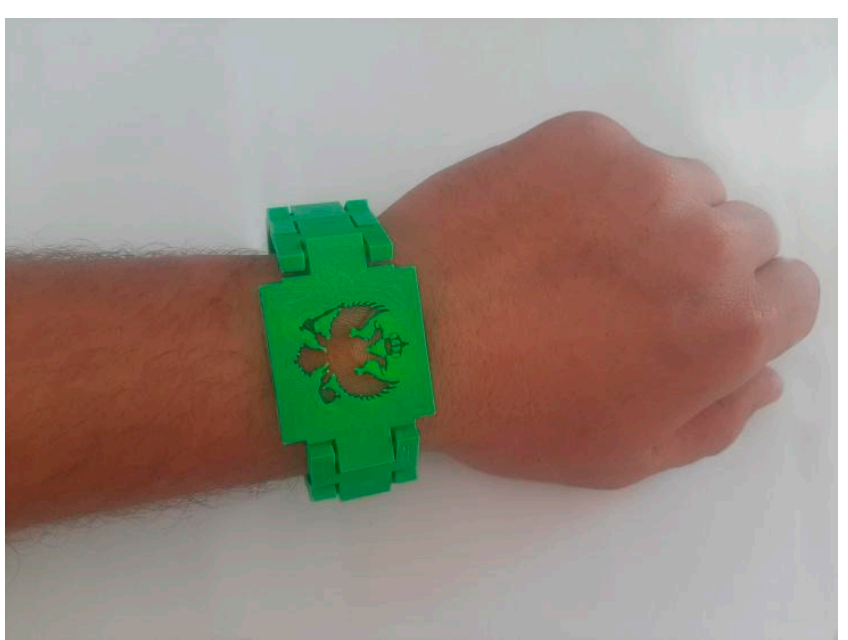

(a)

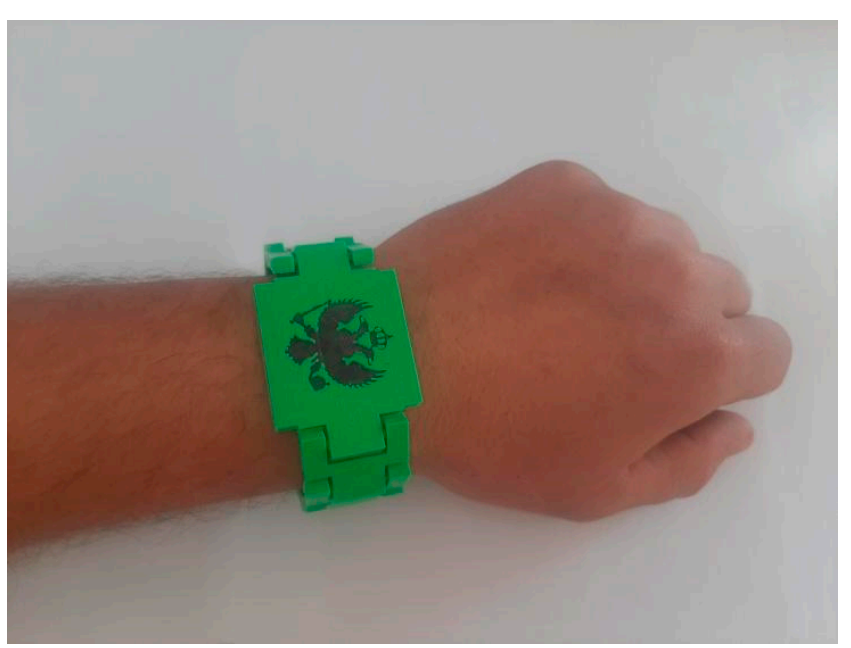

(b)

Figure 11. (a) Patient wearing a bracelet without a high temperature. (b) Patient wearing a bracelet with a high temperature.

\section{Discussion}

This study proposes new 3D-printed thermo-sensored medical gear for detecting one of the most common COVID-19 symptoms: a high human body temperature. In the last several months, we have already witnessed open-source community platforms where designers, makers, artists, engineers, and whole companies have embraced this movement 
and shared their designs and solutions globally. The most produced medical equipment during COVID-19 include face shields, respirators, nasal swabs, and ventilator parts. To date, there are no innovative solutions for medical gear using 3D printing materials that change color due to a high human temperature. The fact that fever has been shown to be a frequent symptom of SARS-CoV2 infection gave us an opportunity to create new and innovative medical gear for detecting COVID-19. In addition, it is not just precise and easy to wear in the shape of a bracelet, but also time-efficient, since in the ongoing second wave of the pandemic in the whole world, the number of medical staff infected by COVID-19 is increasing. In these circumstances, it is difficult to measure the human body temperature often, and therefore a detector of high human temperatures within both medical staff and patients is good to have. This new medical gear has been tested in hospital conditions and shows good and precise characteristics.

\section{Conclusions}

This study concluded that both tested materials-3D-printed tri-color change PLA filament and thermochromic paint-can be used for detecting high body temperatures and implemented as part of thermo-sensored medical gear in the shape of a bracelet. However, this research has shown that more precision in terms of color and time change was shown by the thermochromic paint. The rest of this medical gear can be made of any 3D-printed filament which is comfortable for the hand and wrist. We can see this medical gear being used in a wide number of medical applications.

Supplementary Materials: The following are available online at https:/ / www.mdpi.com/2076-341 7/11/1/419/s1, Figure S1: Process analysis of the thermochromic paint material (a) body temperature $37.2^{\circ} \mathrm{C}$; (b) body temperature $37.5^{\circ} \mathrm{C}$; Table S2: Process analysis of the PLA tri-colour change filament material for body temperature $37.5^{\circ} \mathrm{C}$ for Model \#1 Cube block (a) Specimen 1.1; (b) Specimen 1.5, Table S1: Table 1. Results for measuring colour change for Model \#1 (Cube block) with 3D printing tri-colour change filament in hospital condition; Table S2: Results for measuring colour change for Model \#2 (Stepped pyramid) with 3D printing tricolour change filament in hospital conditions; Table S3: Results for measuring colour change for Model \#3 (Cube block with subtracted pyramid) with 3D printing tri-colour change filament in hospital conditions; Table S4: Results for measuring colour change for Model \#4 (Pyramid with a subtracted pyramid) with 3D printing tri-colour change filament in hospital conditions.

Author Contributions: Methodology, writing, review, and editing, M.D., A.M., J.J., and M.R.; methodology, resources, and conceptualization, M.D., J.J., and V.B.; software, A.M.; formal analysis, M.D. and A.M.; supervision, M.D. and A.M.; funding acquisition, M.D. and V.B. All authors have read and agreed to the published version of the manuscript.

Funding: This research was funded by the Ministry of Science in Montenegro, grant number 02/2062/20-892/2, in the frame of the "3D printing research and innovations-Covid19" project.

Institutional Review Board Statement: The study was conducted according to the guidelines of the Declaration of Helsinki, and approved by the Institutional Review Board (Collegium of Director) of Clinical Centre of Montenegro (protocol code 03/01-sl; date of approval: 04.05.2020.)

Informed Consent Statement: Informed consent was obtained from all subjects involved in the study.

Data Availability Statement: The data presented in this study are available on request from the corresponding author. The data are not publicly available due to privacy.

Conflicts of Interest: The authors declare no conflict of interest.

\section{References}

1. Gibson, I.; Rosen, D.W.; Stucker, B. Additive Manufacturing Technologies; Springer: New York, NY, USA, 2015.

2. Redwood, B.; Schoffer, F.; Garret, B. The 3D Printing Handbook: Technologies, Design and Applications, 1st ed.; 3D Hubs: Amsterdam, The Netherlands, 2017; 304p.

3. Mongeon, B. 3D Technology in Fine Art and Craft: Exploration of 3D Printing, Scanning, Sculpting and Milling; Routledge Publishing: Abingdon, UK, 2016; ISBN 9781315730455. 
4. Tarfaoui, M.; Nachtane, M.; Goda, I.; Qureshi, Y.; Benyahia, H. 3D Printing to Support the Shortage in Personal Protective Equipment Caused by COVID-19 Pandemic. Materials 2020, 13, 3339. [CrossRef] [PubMed]

5. Rendeki, S.; Nagy, B.; Bene, M.; Pentek, A.; Toth, L.; Szanto, Z.; Told, R.; Maroti, P. An Overview on Personal Protective Equipment (PPE) Fabricated with Additive Manufacturing Technologies in the Era of COVID-19 Pandemic. Polymers 2020, 12, 2703. [CrossRef] [PubMed]

6. 3D Printing vs Coronavirus-Process of Printing Protective Visors. Available online: https://www.ntpark.me/en/2020/05/14/3 d-printing-vs-coronavirus (accessed on 14 May 2020).

7. World Health Organization. Rational Use of Personal Protective Equipment (PPE) for Coronavirus Disease (COVID-19): Interim Guidance, 19 March 2020; Institutional Repos Inf Shar 2020:7; World Health Organization: Geneva, Switzerland, 19 March.

8. Roberge, R.J. Face shields for infection control: A review. J. Occup. Environ. Hyg. 2016, 13, 235-242. [CrossRef] [PubMed]

9. Godoy, L.R.G.; Jones, A.E.; Anderson, T.N.; Fisher, C.L.; Seeley, K.M.; Beeson, E.A.; Zane, H.K.; Peterson, J.W.; Sullivan, P.D. Facial protection for healthcare workers during pandemics: A scoping review. BMJ Glob. Health 2020, 5, e002553. [CrossRef] [PubMed]

10. Montenegro: Europe's Last Coronavirus-Free Country. Available online: https://rtmagazine.com/disorders-diseases/infectiousdiseases/other-infections/montenegro-coronavirus-free-europe/ (accessed on 28 November 2020).

11. Worldometers Info. 2020 Coronavirus Update. Available online: https:/ / www.worldometers.info/coronavirus / (accessed on 28 November 2020).

12. Jutzeler, C.R.; Bourguignon, L.; Weis, C.V.; Tong, B.; Wong, C.; Rieck, B.; Pargger, H.; Tschudin-Sutter, S.; Egli, A.; Borgwardt, K.; et al. Comorbidities, clinical signs and symptoms, laboratory findings, imaging features, treatment strategies, and outcomes in adult and pediatric patients with COVID-19: A systematic review and meta-analysis. Travel Med. Infect. Dis. 2020, $37,101825$. [CrossRef] [PubMed]

13. Shang, Y.; Pan, C.; Yang, X.; Zhong, M.; Shang, X.; Wu, Z.; Yu, Z.; Zhang, W.; Zhong, Q.; Zheng, X.; et al. Management of critically ill patients with COVID-19 in ICU: Statement from front-line inten-sive care experts in Wuhan, China. Ann. Intensive Care 2020, 10, 73. [CrossRef] [PubMed]

14. Jean, S.S.; Lee, P.I.; Hsueh, P.R. Treatment options for COVID-19: The reality and challenges. J. Microbiol. Immunol. Infect. 2020, 53, 436-443. [CrossRef] [PubMed]

15. Tri Colour Changing with Temperature 3D Printer Filament. Available online: https://amolen.com/products/amolen-3d-printer-filament-tricolor-changing-with-temperature-black-to-brown-to-yellow-pla-filament-1-75mm-0-03-mm-2-2lbs1kg (accessed on 11 September 2020).

16. Heller, J.; Tatickova, Z.; Kudlacek, J. Research and Development of thermosensitive coating for safety purposes. In Proceedings of the International Conference on Innovative Technologies, Ljubljana, Slovenia, 13-15 September 2017.

17. Wittbrodt, B.; Pearce, J.M. The Effects of PLA Color on Material Properties of 3-D Printed Components. Addit. Manuf. 2015, 8, 110-116. [CrossRef]

18. Desideri, U.; Asdrubali, F. Handbook of Energy Efficiency in Buildings; Butterworth-Heinemann: Oxford, UK, 2018.

19. Thermochromic Powder Pigments. Available online: https://www.atlantachemical.com/tp/tp.html\#tp (accessed on 4 November 2020).

20. Karlessi, T.; Santamouris, M. Improving the performance of thermochromic coatings with the use of UV and optical filters tested under accelerated aging conditions. Int. J. Low-Carbon Technol. 2015, 10, 45-61. [CrossRef]

21. Thermochromic Paints. Available online: https://atlantachemical.com/ (accessed on 4 September 2020).

22. High Quality Thermochromic Products. Available online: https://atlantachemical.com/tpt/tpt.html\#tpt (accessed on 5 September 2020).

23. Wang, X.; Jiang, M.; Zhou, Z.; Gou, J.; Hui, D. 3D printing of polymer matrix composites: A review and prospective. Compos. Part $B$ Eng. 2017, 110, 442-458. [CrossRef]

24. Chacón, J.M.; Caminero, M.A.; García-Plaza, E.; Núñez, P.J. Additive manufacturing of PLA structures using fused deposi-tion modelling: Effect of process parameters on mechanical properties and their optimal selection. Mater. Des. 2017, 124, 143-157. [CrossRef]

25. Fusion 360 | 3D CAD, CAM, CAE \& PCB Cloud-Based Software I Autodesk. Available online: https://www.autodesk.com/ products / fusion-360/ (accessed on 5 June 2020).

26. Craftware I FREE, Fast, Easy-to-Use Slicer Software for Your Digital 3D Objects. Available online: Craftbot.com (accessed on 24 May 2020).

27. Craftbot Flow IDEX XL I The Largest Plug\&Play IDEX 3D Printer. Available online: https://craftbot.com/products/craftbotflow-idex-xl (accessed on 7 June 2020).

28. SOLIDWORKS. Available online: https://www.solidworks.com/ (accessed on 11 June 2020). 